\title{
A Web-Based Farm 3D Visualization Management System
}

\author{
Afolayan Obiniyi and Abubakar Ibrahim*
}

Department of Mathematics, Ahmadu Bello University, Zaria, Nigeria

\begin{abstract}
Web based farm management system is the collection of processes and information that is used to manage various phases of a farm and accessible on the Internet. The paper is aimed to improve the way information disseminates to farmers. It is needed for the development of agriculture to improve the life of farmers. The paper examines the basic visualization of farm in 3D form for Jigawa state farming environment. This means that, how plant of the area will be view virtually. The paper started with examining some bodies that work on agricultural activities based on how they improved in agricultural technology and how to improve the flow of information of agricultural activities through modern channels for sustainable agriculture and rural development. It looks at the design of 3D farmer's visualization technology and the implementation of the model.
\end{abstract}

Keywords: Farm management; Google earth; 3D visualization; Agriculture; Farmers

\section{Introduction}

Information technology support in the Agricultural growth in some ways, but the olden days of practicing agriculture is not enough for the developing world. However, the need for modern information dissemination to agriculture is very important so that it could be used to all part of the world.

Farming has been a part of human life long ago and the need for agricultural information is also old. Increase in rapid developments in computer technology and disseminating its information and the accessing of information related to geography are all come together to provide a new effort to Geographical Information Systems (GIS). Since Information is the key for success in all agricultural activities, therefore it is believe that, GIS and Google Earth serve as an instrument for information dissemination in agriculture.

Digital globes are sometimes referred to as digital earths. It is preferred that, the term digital globe much like a physical globe; they are a representation of the Earth's surface. Digital globes are webenabled digital representations of the Earth's surface. It allows tapping into vast repositories of spatially indexed information. As a result, they are changing the way it interact with and display geographic information, and may enhance the ability to visualize geographic information [1]. These developments may have the potential to modify spatial understanding of geographic phenomena. Digital globes provide user the ability to shift between scales swiftly and seamlessly, move quickly to any location on the globe, and view the world in two or three dimensions [2].

Although the technology of digital globes has been available for a long time since 1992, hence, digital globes are now common software found on everyday desktop computers. By providing underlying high quality satellite and aerial imagery, digital globes provide an excellent tool to publish spatial information, help in the teaching of earth sciences [3] and promote an overall better understanding of spatial processes and information accessing.

\section{Review of Related Work}

Developed "Uganda Rural Agricultural Information System (URAIS) Model" The model highlight structural elements through which information process activities should be performed to realize the goal of accessing and utilizing agricultural information by the rural women in Uganda [4]. The purposes of URAIS are, Develop infrastructure including buildings, power, telephony and other communication facilities for example satellites and information providers. These are the foundation of ICTs application to the access and utilization of agricultural information services by the Rural Women. Establish the facilities infrastructure-libraries/resource centres/Telecentres, cyber cafes, wired villages and rural community centres. These are places where the people would gather and consume information services and produce and distribute information resources such as posters, pamphlets, basic primers, video, films, instruction and discussion programs, according to the established Agriculture information needs [4].

In a web-based system that allows the farmers to access the information about rice cultivation in their area was developed [5]. Farmers can get instant access and information to improve their rice production, which is vastly beneficial for them. As a result, a good relationship will be built among farmers and farm managers and policy makers. The research attempts to generate an online GIS Decision Support System (DSS) for paddy precision farming by using Map Guide Open Source (OS) and investigates its mapping capabilities [6]. The E-paddy modules has 3 major modules; whereby users are able to view the map via internet using map server, paddy yield information for each season and Paddy GIS, which is a system for paddy precision farming. Information how to control the fungus, weed and pest is provided. The user can enter the name of the fungus and the system will return the query results for the types of control steps to be taken [5].

Geographical Information Systems (GIS) can play a major role at enhancing Sub-Saharan Africa's agricultural development. The crucial role of multilingual GIS is anticipated at the level of extension messages delivery to land users via visual displays, maps and relevant linguistic interpretations. Research data are important to the end user at the

*Corresponding author: Abubakar Ibrahim, Department of Mathematics, Ahmadu Bello University, Zaria, Nigeria, Tel: 08034597856; E-mail: abubakaribrahimkainuwa@yahoo.co.uk

Received December 02, 2014; Accepted December20, 2014; Published January 10,2015

Citation: Obiniyi A, Ibrahim A (2015) A Web-Based Farm 3D Visualization Management System. J Comput Sci Syst Biol 8: 049-054. doi:10.4172/jcsb. 1000170

Copyright: ( 2015 Obiniyi A, et al. This is an open-access article distributed under the terms of the Creative Commons Attribution License, which permits unrestricted use, distribution, and reproduction in any medium, provided the original author and source are credited. 
prescriptive level, and not at the stage of hypothesis testing. In many scientific systems of learning for example, in soil science, botany and geology, these are a form of special languages intended to facilitate the understanding of scientific domains of common interest [7].

Some of the projects that enable information related to geography can be seen as:

\section{SIBWA}

This project intended to demonstrate the value of very highresolution imagery (VHRI). In June 2009, the Seeing is Believing-West Africa (SIBWA) project, started working with six communities of farmers in the region-three in Mali, and one each in Ghana, Burkina Faso and Niger. Led by the International Crops Research Institute for the Semi-Arid Tropics (ICRISAT), the SIBWA team provided the farmers with very high-resolution imagery (VHRI) of their land. The images are made by sensors on satellites and show a high level of detail. The intention is to give farmers in West Africa information on soil fertility and accurate land size to plan and manage their crops for the coming growing season [8].

\section{Africa Soils Information Service (Afsis)}

This four-year project (2010-2013) is intended to fill the current gap in soil information by developing an accurate soil map for the whole of Africa in order to help farmers maximize the use of their land, and to assist agronomists and extension agents to plan and develop methods for improving soil fertility. Part of Afsis involves taking samples of soil from selected sites. Handheld personal Digital Assistance (PDA) devices fitted with GPS receivers document the exact sampling location. Remote sensing technology and the analysis of high-resolution satellite imagery provide further details on soil moisture, nutrients and organic content. This information also gives a broader overview of soil properties in places that have not been sampled. The resulting soil map can show the properties of soil throughout the continent in blocks representing areas of land measuring $90 \times 90$ meters. This gives the map a resolution 100 times greater than any previous soil map. The soil map will be available for free on the Internet, and continually updated [9]. The high resolution of the map means that farmers can zoom in to see the condition of the soil on their land. The project will also look at other ways to make the data available, via mobile phones. The project is led by the International Center for Tropical Agriculture (CIAT) in Nairobi (Kenya) and funded by the Alliance for a Green Revolution in Africa (AGRA) [9]. Other projects are:

\section{Nokia life tools}

Launched in India in 2008, Indonesia and China in 2009. Information related to commodity prices, commodity news, agriinputs (seed, fertilizer and pesticides) prices, weather forecasts and agricultural tips \& techniques. In Indonesia, instead of market price, which is the main focus in India, Nokia Life tools concentrates on information related to animal husbandry, fisheries, etc. The information is pushed daily via text messages [10].

\section{Pakistan}

Pakistan Pakistan.com is the first and largest agricultural web portal in Pakistan, providing a platform where the entire agri-community can connect with each other, sharing ideas, experiences and information. Viewable in both English and Urdu, the portal offers features like the latest news and issues from around the world as well as inside Pakistan. There are also advisory, report and business center sections, including a regular special report on important aspects of agriculture [10].
However, it is discloses that farmers required specific information at the right time in a suitable manner through Medias such as social networks, internet, which is easily accessible by them. Disseminating Information through GIS and Digital globe via 3D model along with their mode of delivery can be more improved to receivers. Then this shows that, all the existing works reviewed are not 3D enabled. If you look at the reviewed works and project, you will find that the work done is in two dimensions i.e. you can see the work like a picture looking thing. So our research is on $3 \mathrm{D}$ that means the work is virtual in nature.

\section{System Requirement}

The requirements of the system for the designing of farmer's 3D visualization technology for this research are; there is need for Google Earth Pro installed on your computer. A desktop GIS currently popular ArcGIS of ESRI is also installed for the designing of the maps. The last one to be installed is the sketchup or Google sketchup and Ruby programming language 2.0. The information of jigawa State web based farm management system on how the farmers will decide on farming process can develop.

\section{System architecture}

The system is designed as a software architecture consisting of three layers, thus GIS map layer, Data layer and interface layer (Figure 1). The layers of the Architecture are:

GIS map layer: The layer of GIS map consists of jigawa state map as the zones created by the state agriculture department and the local governments under each zone. An important part of the designing of a GIS system in this work is constructing the map of jigawa state where the four zones of agricultural process are separated. The map can be constructed using desktop ArcGIS.

The map contained data from the Jigawa State. It contained feature classes that were created from coordinates which stored GIS maps. The application in the paper has a user interface where the GIS map can be view. Geodatabase was used in the system to store the data used in developing the maps of the state. The map of local government consist of the tip that can allow the user to decide on the area to choose either the link to Google earth in which model can be view or link to PDF file for farm and farm management information.

Data layer: The data layer contains two modules: the Geodatabase

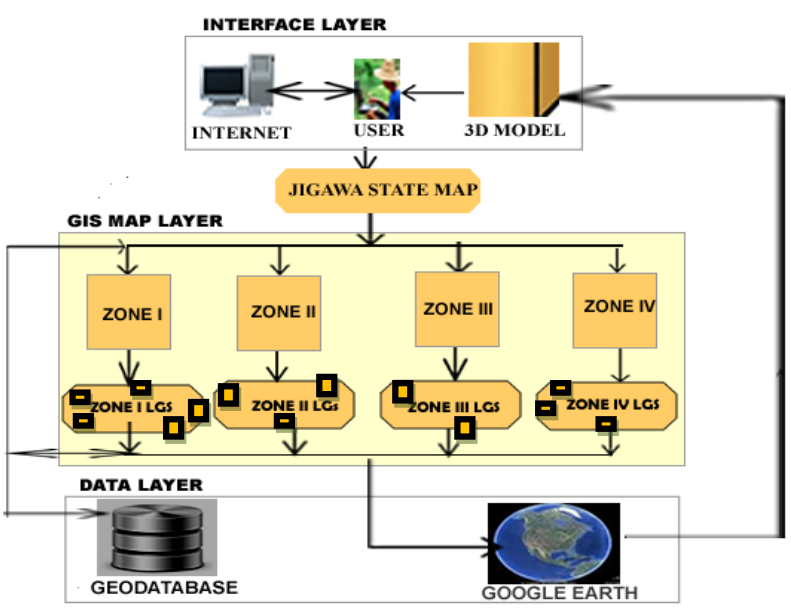

Figure 1: Architecture of the farmers' 3D visualization Technology. 
and the Google earth. The modules control the georeference data and non georeference data used in the application.

Geodatabase: Geodatabase also call Geographical Database is a GIS database which serve as the computer-based representation of the real world. A database or file structure used primarily to store, query, and manipulate spatial data. Geodatabases store geometry, a spatial reference system, attributes, and behavioral rules for data. Various types of geographic data sets can be collected within a geodatabase, including feature classes, attribute tables, raster data sets, network data sets, topologies, and many others [11].

File geodatabase was used in the paper, it contains file geodatabase which collect various types of GIS datasets held in a file system folder. This is the recommended recent data format for ArcGIS stored and managed in a file system folder. The feature classes of the geodatabase of this paper consist of the state map, zones, local governments and farm parcels, where all are grouped together in a file geodatabase feature dataset. The file geodatabase have file attachments to the records of a geodatabase feature class. The attachments are stored internally in the geodatabase in a separate attachment table. The Attachments contains input records of pdf and 3D model in . $\mathrm{kml}$ file. The $\mathrm{kml}$ file used in the paper is to

(i) Display 3D model data as elements within Google Earth.

(ii) Have a. $\mathrm{kmz}$ file extension (for compressed and zipped KML files).

Google earth: Google earth provides aerial views in various resolutions of the world, and permits smooth navigation by dragging the mouse. Associated with Google's powerful search engine, Google earth offers the service of finding a specific area on the map - users can quickly find a location by entering an address or the name of general area. Also, like other online map services, Google Maps provides the users with a driving direction service. They can get a step by step list of how to get to the destination and an estimated travel time [12]. In the paper, when the tip from GIS map shows link for Google earth, it will take the application to the Internet where Google earth can be used to view jigawa state imagery satellite area that contains local governments where the major plants can be import to view in 3D model using $\mathrm{kml}$ code

Interface layer: The interface layer is the layer that allows inputting the data to the system through the Internet and producing the output as 3D model by the user. The components in the layer are:

User: This is system interface where farmers can use to have access to the maps of the application. The system has been developed using Hypertext Pre Processor (PHP) and HTML which establishes a web connection that enables users to view GIS map. Therefore, from the interface the user can link to the map and then to Jigawa state where zones can be identified.

Internet: Internet make globe a decrease effect, were every kind of data is just simple clicks away. The time now has come to achieve this medium for our need in the fields of agriculture. In this architecture the internet was used to permit user to have accesses to overall GIS map to look for his request, it also allow user get his output in text and 3D model.

Three dimensional models: SketchUp is a $3 \mathrm{D}$ modeler or a $3 \mathrm{D}$ modeling program integrated with Google Earth. The program is created by "@Last Software Company" in august 2000 as a general 3D content creation tool. In [13] ruby is the programming language that can be used to extend SketchUp capabilities in the paper. Three Dimensional model of the farm can be import on the earth map of Google earth under jigawa state areas.

Dataflow: The Dataflow of the farmers 3D visualization technology as shown in Figure 2 was started with the stat terminal as user intefare, where people accessed internet in order to look for the farm mangement portal of the jigawa state farming system using computer. The user in using interface search for jigawa map image and look for the zone of his choice between four zone viz; zone I, II, III, and IV. From there, the overall map of jigawa state displays were he can choose for the zones created in GIS forms, that will take him to local government map of any zone he choose. From the local government the user click on the area were he will decide on either model of $3 \mathrm{D}$ or the information of land and farm in pdf form as text. If his decision is 3D model that is yes as shown in the flowchart, the Google earth will displays 3D visualization of farm with an example of major crop grown in the area, then the program terminate. When the user select other round, that is no as shown in the chart, it will take him to textual output, where the information comprised the farm and land in pdf. Then the chart terminate

\section{Design GIS map}

The GIS Map of the zones was designed using ArcGIS 10 from ESRI. The ArcMap part of the ArcGIS helps in the designing of the maps. ArcMap is the comprehensive map authoring and data analysis component of ArcGIS. It's the application the work used for analyzing and mapping of the data. The Table 1 below shows the geodatabase use in the mapping of Zone II and other information associated with a spatial location used.

\section{Designing 3D farm model}

The 3D farm model was designed using ruby programming language as an extension of SketchUp abilities. Ruby is an interpreted scripting language for quick and easy object-oriented programming.

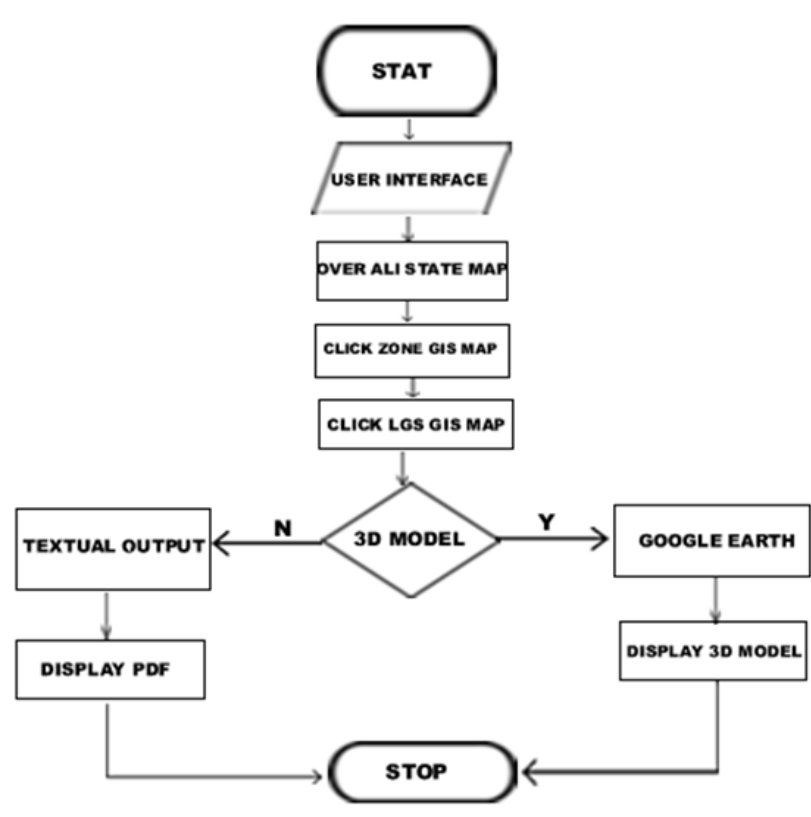

Figure 2: Data flow Diagram of the farmers' 3D visualization Technology. 


\begin{tabular}{|c|c|c|c|c|c|}
\hline Object id $^{*}$ & Shape* $^{*}$ & Shape_Length & Shape_Area & LGA & $\begin{array}{c}\text { No_of_- } \\
\text { farm_parcel }\end{array}$ \\
\hline 2 & Polygon & 198121.6551 & 1335913499 & GARKI & 2 \\
\hline 3 & Polygon & 67796.61867 & 232767100.5 & GUMEL & 2 \\
\hline 4 & Polygon & 112407.9705 & 666482850.2 & MAIGATARI & 2 \\
\hline 5 & Polygon & 141983.8226 & 866387734.4 & GAGARAWA & 2 \\
\hline 6 & Polygon & 167923.5495 & 920590938.3 & RINGIM & 2 \\
\hline 7 & Polygon & 138365.7067 & 650871192.5 & TAURA & 2 \\
\hline
\end{tabular}

Table 1: Geodatabase Table of local Governments of zone 2.

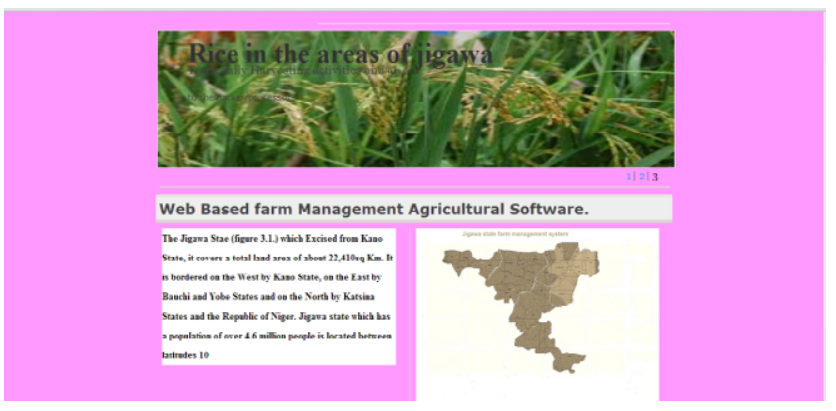

Figure 3: User Interface.

Most importantly for the paper, it's a language that SketchUp can understand via its SketchUp Ruby API. The paper used ruby to write its scripts within ruby code editor program and saved as .rb files. These files are then loaded to allow code editor which is attached to Sketchup on displaying the farm model.

\section{System Implementation}

This section explains the implementation and discussion of the result. First, the main features and the implementation of this tools and platform will be discussed. The second part will elaborate on the implementation of 3D visualization technology of the system that has been developed. The modeling of the 3D effect and accessing of the Google earth was done lastly.

\section{Tools and platforms}

The tools and platform used in the implementation of the proposed 3D Model involve the following:

Google Earth: Digital globe tools such as Google Earth is used for accessing geospatial data in field like agriculture. These tools provide a simple means of visualizing, different datasets based on a global view. Google Earth was used in the paper for visualizing the farm model.

Keyhole Markup Language (KML): KML is a computer language family of XML applied to Google Earth and a file format used to display geographic data in an Earth browser such as Google Earth. The paper used it to make data export and viewed on Google Earth.

ArcGIS: ArcGIS desktop was used in the research for mapping the area of jigawa state. The work dealt with its two components those:

ArcMap: ArcMap is the main component of ArcGIS suite of geospatial processing programs. It is used in paper to design map in 2D. Maps created and saved within ArcMap stored in .mxd extension.

ArcScene: Is the second component of ArcGIS, which the research used to make the work develop by Arcmap in 3D form.

Ruby programming language: Ruby scripts were used in basic text editing program and save in the .rb files. The work uses ruby code editor for creating scripts in farm modeling with help of Sketchup.

Google sketchup: Google Sketchup is software developed by Google. It has tool that allows 3D construction of objects using a set of tools provided. But the paper makes used of ruby and these tools for creating 3D structure of farm.

Collada: COLLADA is an attempt for establishing an interchange file format for interactive virtual environments. COLLADA is use to convert the model from sketchup to model in order to allows KML load on Google earth.

\section{Implementation outputs}

This is the user interface were users can use internet to access the web site of farmer's 3D farm. The farmer or user will lastly receive the information from jigawa state based on 3D model. The interface looks in (Figure 3).

Zone searching: (Figure 4a) shows a 2D view of Zone I part of jigawa state Agricultural location, according to Jigawa State Agricultural and rural development authority. The Zone consists of seven local governments. The zone was produced using ArcGIS to shows the farm parcel in each local government as example of farm. The 3D form of Zone1 is shown on (Figure $4 \mathrm{~b}$ ), while Table 2 is a table of geodatabase used in Zone1 farm parcel for developing the map zone.

\section{Modeling the 3D effect}

The three dimension of one of the major plant grown in jigawa state known as sesame. It is one of the oil producing crops in the world. The plant developed using sketchup software as shown in (Figures 5 and 6) shows the sesame farm, which developed using Ruby programing language with help to improve the ability of sketchup. Ruby code editor became the environment for writing multiple line of code in the work.

\section{Accessing the google earth}

After the plant was design Google earth was used to load the farm on the area of the local government in the state. This is done using generating the farm in to COLLADA file format, then KML was wrote to load the farm on Google Earth.

\section{Advantages of the Proposed Work over an Existing System}

A. The paper develops on three dimensional models, which is not available on other work done previously, especially in Northern part of Nigeria.

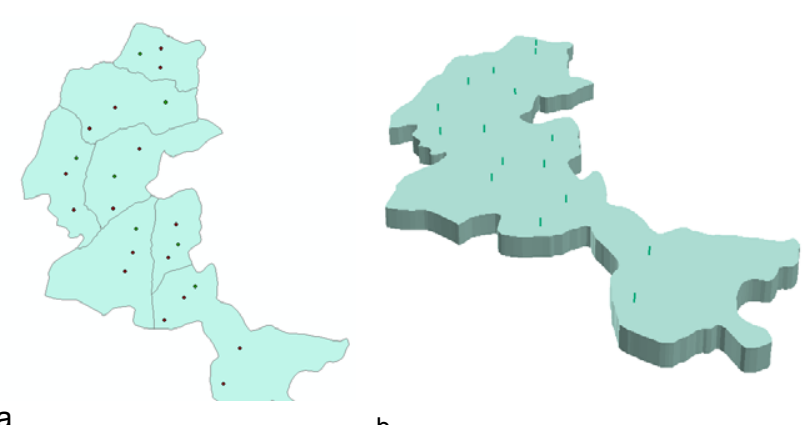

a b

Figure 4: Zone1 in 2D and 3D Model. 
Citation: Obiniyi A, Ibrahim A (2015) A Web-Based Farm 3D Visualization Management System. J Comput Sci Syst Biol 8: 049-054. doi:10.4172/ jcsb. 1000170

\begin{tabular}{|c|c|c|c|c|c|c|c|c|}
\hline Parcel no & Location_X & Location_Y & L_G_A & Village_Town & Soil_type & $\begin{array}{c}\text { Name_of_farm_ } \\
\text { officer }\end{array}$ & $\begin{array}{c}\text { Farm_officer__ } \\
\text { phone }\end{array}$ & $\begin{array}{c}\text { No_of_plot_per_ } \\
\text { parcel }\end{array}$ \\
\hline JSFM/14/01 & 599489 & 1218536 & Gwaram & Gwaram & Sandy & Mr. AA & 80333333 & 5 \\
\hline JSFM/14/02 & 606050 & 1232718 & Gwaram & Gwaram & Sandy & Mr. AA & 80333333 & 4 \\
\hline JSFM/14/03 & 575570 & 1244148 & Gwaram & Gwaram & Sandy & Mr. AA & 80333333 & 5 \\
\hline JSFM/14/04 & 583614 & 1253038 & Gwaram & Gwaram & Sandy & Mr. AA & 80333333 & 4 \\
\hline JSFM/14/05 & 577052 & 1269125 & Buji & Buji & Sandy & Mr. Ali & 90887888 & 3 \\
\hline JSFM/14/06 & 580227 & 1282671 & Buji & Buji & Sandy & Mr. Ali & 90887888 & 4 \\
\hline JSFM/14/07 & 562870 & 1271241 & Birnin-ku & Birnin-ku & Sandy & Mr. Amos & 80777777 & 4 \\
\hline JSFM/14/08 & 559695 & 1263621 & Birnin-ku & Birnin-ku & Sandy & Mr. Amos & 80777777 & 3 \\
\hline JSFM/14/09 & 555039 & 1289021 & Kiyawa & Kiyawa & Sandy & Mal. Abubakar & 81555555 & 5 \\
\hline JSFM/14/10 & 538952 & 1288598 & Dutse & Dutse & Sandy & Mal. Isa & 123456789 & 5 \\
\hline JSFM/14/11 & 535777 & 1302991 & Dutse & Dutse & Sandy & Mal. Isa & 123456789 & 5 \\
\hline JSFM/14/12 & 565622 & 1313151 & Kiyawa & Kiyawa & Sandy & Mal. Abubakar & 81555555 & 3 \\
\hline JSFM/14/13 & 545514 & 1321406 & Jahun & Jahun & Sandy & ibrahim & 815452000 & 4 \\
\hline JSFM/14/14 & 555674 & 1329873 & Jahun & Jahun & Sandy & ibrahim & 805452000 & 5 \\
\hline JSFM/14/15 & 574089 & 1345960 & Miga & Miga & Sandy & ibrahim Miga & 808888888 & 5 \\
\hline JSFM/14/16 & 574300 & 1353580 & Miga & Miga & Sandy & ibrahim Miga & 808888888 & 4 \\
\hline
\end{tabular}

Table 2: Attribute Table of Zone1 Farm parcel.

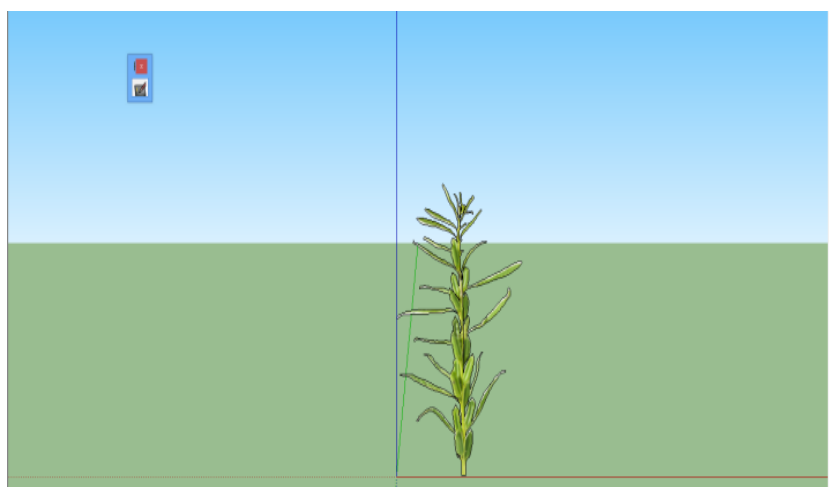

Figure 5: 3D Model of Sesame Plant.

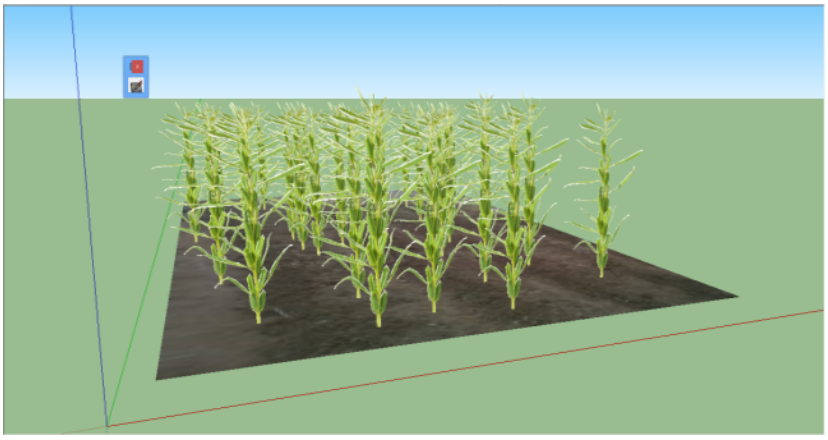

Figure 6: 3D models Sesame Plant Farm.

B. Local farm design in the model will allows the people or farmers to view the virtual farm and feel as real farm to choose the improved crop variety among the major crop grown in the area.

C. The existing work is based on $2 \mathrm{D}$ work, which is flat looking object like, but the proposed work was solid looking like sculpture, this will help in providing virtual looking object like farm resembles real world.

D. Disseminating of the required information to farmers will be more consider and more improve in $3 \mathrm{D}$ than the existing work.

\section{Conclusion}

The paper look at the web based farm management: an approach of three dimension visualization. It is aimed at developing a plant and farm model of the jigawa state major crops produce in the state communities through GIS and Google Earth 3D technologies in order to allows farmers and other rural families view the virtual world of the farm for better decision in choosing the appropriate crop toward valuable farming activities

It examined the reviewed works, which include the work of other people and the project work based on the farming. The paper continues with the designer of 3D farmer's visualization, were the architecture of the work designed with three layers. The design of GIS map and that of 3D model was made. Finally the implementation of the work was done.

Traditionally, two dimensional design is less viewable, since it is much of $\mathrm{x}$ and $\mathrm{y}$ dimension, and it is a picture like view object. But, 3D designs is always shown and reach in $\mathrm{x}, \mathrm{y}$ and $\mathrm{z}$ dimension which can rotate and move in such a way people will feel like a real life world. The plants are in 3D design, so it can be viewed as real life plants. 3D plant model was preferred because of its interactive ability to disseminate information to farmers and other people. Its interactive ability will help in developing and enriching agricultural product as well as well-being of the farmers. It will also help in reducing the global hunger in rural community.

This work presents the conceptual architecture of the farmers using three dimensional visualization applications which consists of three layers via: interface, GIS map and data layer. The layers combined together to form a clear and interactive vision of 3D model for reliable accessing of information by farmers to generate high Agricultural productivity.

\section{Recommendation}

Information dissemination through GIS and Google earth technology to farmers for better productive agriculture in the area of study recommend the following:

(i) The farmers will participate in other information and communication technology, so that they will improve in day to day activities of internet toward retrieval of modern way of information concerning farming. 
Citation: Obiniyi A, Ibrahim A (2015) A Web-Based Farm 3D Visualization Management System. J Comput Sci Syst Biol 8: 049-054. doi:10.4172/ jcsb.1000170

(ii) Government and private providers of information need to work together with farmers to find precise needs of information that would assist them to develop a better farming product and to find more operative communication channels in which to access better information for farming.

(iii) There is needed to look at phases like education, farming experience and women farmers when disseminating information. This means that it will consider illiterate farmers, local farmers and women farmers when spreading information.

\section{References}

1. Miller C (2007) A beast in the field: The google maps mashup as GIS/2, Cartographica. The International Journal for Geographic Information and Geovisualization 41: 187-199.

2. Rouse L, Bergenon S, Harris T (2007) Participating in the geospatial web: Collaborative mapping, social networking and participatory GIS. In A. Scharl, \& K. Tochterman (Eds.), The geospatial web: How geobrowsers, social software and web 2.0 are shaping the network society. London: Spring. pp. 153-158.

3. Aurambout, C Pettit J, Sheth F, Bishop I (2010) Virtual farming systems to communicate climate change impact data to farming communities. WS1.7Virtual realities and the future of distance learning in rural areas.
4. Sarah, B. K. (2011) Information and Communication Technologies (ICTs) contribution to the access and utilization of agricultural information by the rural women in uganda.

5. NikNorasma C, Abdul Rashid M, Mohd Amin M, Khairunniza B, Ahmad R (2010) Generating online GIS Decision Support System for Paddy Precision Farming.

6. Kang-Tsung C (2009) Introduction to Geographic Information Systems with Data Files CD-ROM. McGraw-Hill Companies , $5^{\text {th }}$ edition.

7. Brian J. (2009) A Multilingual Geographical Information System (GIS) for Dissemination of Agriculture Information: A Framework For Sub-Saharan Africa.

8. (2013) SIBWA.

9. (2013) Africa Soils Information Service (Afsis).

10. Fritz B (2010) Mobile Applications in Agriculture: mAgriculture.

11. United nation New York (2000) Handbook on geographic information system and digital mapping: A United Nations Publication Series F No. 79.

12. Zhennan S (2007) A Web-based Geographical Information System for Low Bandwidth Access.

13. Dominique D (2009) Supporting smart entity behavior across virtual environment platforms. 